\title{
Crítica trascendental del sentido y validez Acerca del alcance normativo de las reglas del discurso en la pragmática trascendental del lenguaje
}

\section{Transcendental criticism of meaning and validity About the regulatory scope of discourse rules in language transcendental-pragmatics}

\author{
LEANDRO PAOLICCHI \\ Universidad Nacional de Mar del Plata - CONICET (Argentina)
}

Recibido: 21/01/13 Aprobado: 22/04/2013

\begin{abstract}
RESUMEN
En el presente trabajo se aborda el problema fundamental que concierne a la pragmática trascendental del lenguaje referido al alcance normativo de las reglas del discurso. Luego de presentar las características fundamentales que estas reglas manifiestan en la pragmática trascendental (I), se desarrolla la discusión en torno a su alcance normativo (II). Reconstruyendo y criticando la solución de Karl-Otto Apel a esta problemática (III) se presenta esquemáticamente una propuesta de solución (IV) y finalmente se extraen algunas conclusiones que pueden ser tenidas en cuenta para futuros desarrollos de esta propuesta (V).
\end{abstract}

PALABRAS CLAVE

PRAGMÁTICA, LENGUAJE, SENTIDO, ACCIÓN, VALIDEZ

\section{ABSTRACT}

This paper addresses the fundamental problem concerning transcendental pragmatics of language referring to the regulatory scope of the rules of discourse. After presenting the main features that these rules manifest in the transcendental pragmatics (I), we develop the discussion

(C) Contrastes. Revista Internacional de Filosofia, vol. XIX-N² (2014), pp. 229-247. ISSN: 1136-4076

Departamento de Filosofía, Universidad de Málaga, Facultad de Filosofía y Letras Campus de Teatinos, E-29071 Málaga (España) 
about their regulatory reach (II). Reconstructing and criticizing Karl-Otto Apel's solution to this problem (III), we propose a solution schematically (IV) and finally, we draw some conclusions that can be considered for future development of this proposal $(\mathrm{V})$.

KEYWORDS

PRAGMATIC, LANGUAGE, MEANING, ACTION, VALIDITY

\section{LAS CARACTERÍSTICAS FUNDAMENTALES DE LAS REGLAS DEL DISCURSO EN LA PRAGMÁTICA TRASCENDENTAL DEL LENGUAJE}

Sobre la baSE de LA PRAGMÁtica tRASCENDENTAL del lenguaje, desarrollada por Karl-Otto Ape ${ }^{1}$ y como un desprendimiento de su dimensión normativa, se ha bosquejado también la fundamentación de una ética. La fundamentación ética queda comprendida dentro de la pragmática trascendental del lenguaje, en el sentido de una fundamentación de los presupuestos o de las condiciones de posibilidad de la argumentación. Es decir, cuando discutimos o argumentamos en torno a una cuestión determinada hacemos presuposiciones de tipo

1 Para una visión completa del desarrollo de la pragmática trascendental puede verse K.-O. Apel, Transformation der Philosophie. Frankfurt am Main: Suhrkamp, 1973, II Bde.; Id., «Sprechakttheorie und tranzendentale Sprachpragmatik zur Frage ethischer Normen» en Id. (Hrsg.), Sprachpragmatik und Philosophie. Frankfurt am Main: Suhrkamp, 1976; Id., Auseinandersetzungen in Erprobung des transzendentalpragmatischen Ansatzes. Frankfurt am Main: Suhrkamp, 1998; Id, «Intersubjektivität, Sprache und Selbstreflexion», en W. Kuhlmann (Hrsg.), Anknüpfen an Kant. Konzeptionen der Transzendentalphilosophie. Würzburg: Königshausen und Neumann, 2001; Id., «Transzendentale Intersubjektivität und das Defizit einer reflexionstheorie in der Philosophie der Gegenwart», en H. Burckhart und H. Gronke (Hrsg.), Philosophieren aus dem Diskurs. Beiträge zur Diskurspragmatik. Würzburg: Königshausen \& Neumann, 2002; D. Böhler, Rekonstruktive Pragmatik. Von der Bewußtseinsphilosophie zur Kommunikationsreflexion: Neubegründung der praktischen Wissenschaften und Philosophie. Frankfurt am Main: Suhrkamp, 1985; Id., «Wohin führt die pragmatische Wende? », en Id., T. Nordenstam und G. Skirbekk (Hrsg.), Die pragmatische Wende. Sprachspielpragmatik oder Transzendentalpragmatik? Frankfurt am Main: Suhrkamp, 1986; Id., «Dialogreflexion als Ergebnis der sprachpragmatischen Wende. Nur das sich wissende Reden und Miteinanderstreiten ermöglicht Vernunft», en J. Trabant (Hrsg.), Sprache denken. Positionen aktueller Sprachphilosophie. Frankfurt am Main: Fischer Taschenbuch Verlag, 1997; Id., «Dialogreflexive Sinnkritik als Kernstück der Transzendentalpragmatik. Karl Otto Apels Athene im Rücken», en D. Böhler, M. Kettner und G. Skirbekk (Hrsg.), Reflexion und Verantwortung. Auseinandersetzungen mit Karl-Otto Apel. Frankfurt am Main: Suhrkamp, 2003; W. Kuhlmann, Reflexive Letztbegrünndung, Untersuchungen zur Transzendentalpragmatik. Freiburg: Alber, 1985; Id., «Transzendentalphilosophie nach dem linguistic turn», en Id., Kant und die Transzendentalpragmatik. Würzburg: Königshausen \& Neumann, 1992. 
normativo ${ }^{2}$ que hacen posible que la argumentación tenga sentido y pueda cumplir con alguno de los objetivos por los cuales se la lleva adelante. Es precisamente dentro de éstas condiciones de posibilidad de la argumentación donde se encuentra el principio de la ética del discurso. Dicho principio enuncia: sólo pueden pretender validez las normas que se encuentran (o podrían encontrar) aceptación por parte de todos los afectados como participantes en un discurso práctico. Este principio, en tanto resultado de la transformación pragmático lingüística de la ética kantiana, reemplaza al imperativo categórico como principio de universalización y funciona como una idea regulativa al señalar que las máximas deben ser acordadas por todos los afectados. ${ }^{3}$

El bosquejo de una «ética del discurso» no resulta acabado con la reconstrucción de un principio ético a partir de las reglas que hacen posible la argumentación. Todo el proyecto práctico de la pragmática trascendental del lenguaje consiste también en la reconstrucción precisa de un conjunto de reglas del discurso en las cuales se ha puesto de relieve con claridad su contenido ético. Son un conjunto de estos presupuestos de la argumentación, es decir, las reglas del discurso con claro contenido práctico, los que terminan de delinear el carácter sistemático de la ética del discurso.

Es fundamental dejar en claro que la reconstrucción de un conjunto de presupuestos de la argumentación con contenido ético no tiene como objetivo simplemente establecer un conjunto de normas para los que argumentan. Jamás se ha pensado desde la pragmática trascendental en una ética para la argumentación, sino para todas las acciones en general. Es decir, la ética del discurso no prescribe normas sólo para aquellos que realizan acciones discursivas, sino para todos los tipos de acciones que le es posible realizar a los hombres. ${ }^{4}$

En este sentido, Apel ha pensado una continuidad entre aquello que las reglas del discurso prescriben y las acciones de todos los hombres en el mundo de la vida. Las normas que los presupuestos de la argumentación prescriben para aquellos que se involucran en un intercambio de argumentos valen también para aquellos que no toman parte explícitamente en discusiones y simplemente realizan sus acciones cotidianas normalmente. Si no se diera por sentada esta continuidad no se podría hablar de una ética del discurso y tendríamos que

2 Debe aclararse que este tipo de presuposiciones no son las únicas que se realizan cuando se argumenta. Cuando se discute mediante argumentos se presuponen también otro conjunto de elementos que no tienen un contenido específicamente normativo.

$3 C f$. K.-O. Apel, Auseinandersetzungen in Erprobung des transzendentalpragmatischen Ansatzes. Frankfurt am Main: Suhrkamp, 1998, pp. 625-626.

4 Cf. Id., Transformation derPhilosophie, II Bd.. Frankfurt am Main: Suhrkamp, 1973, pp. 378-380 y Diskurs und Verantwortung. Das Problem des Übergangs zur postkonventionellen Moral. Frankfurt am Main: Suhrkamp, 1988, p. 116. 
pensar efectivamente en la ética del discurso como una ética para la argumentación. Pero de esta manera no podríamos hacer frente a los objetivos trazados por la ética del discurso. Darles la facultad a los hombres de hacerse cargo de los procesos que amenazan su supervivencia sobre la tierra, es decir, hacerlos responsables por las consecuencias de los avances de la tecnociencia, no puede hacerse con la reconstrucción de un conjunto de obligaciones que sólo valen para aquellos que toman parte en intercambios argumentativos.

Junto con esta continuidad establecida entre las reglas del discurso y las acciones no discursivas viene adosada como su consecuencia inevitable otra característica de gran relevancia que define a las reglas de la argumentación. Si existe una continuidad entre ellas y las acciones de los hombres, ello significa que la validez de esas reglas no depende de determinadas circunstancias, de la adopción de determinados roles, ni se suspende frente a determinadas situaciones. La continuidad entre las reglas del discurso y las acciones de los individuos fuera de éste establece que la validez de dichas reglas es categórica y no depende de la voluntad de los sujetos de someterse a ellas o no, de tomar parte en argumentaciones o no, de adoptar el rol de participante en una discusión o no.

El problema central tratado en este trabajo está determinado por estas dos características de los presupuestos de la argumentación: su continuidad normativa con las acciones de los hombres en el mundo de la vida y su validez categórica. Es decir, la cuestión abordada aquí es si las reglas que se han reconstruido como constitutivas dentro del discurso pueden trasladar su normatividad a las acciones en el mundo de la vida que no son prima facie acciones lingüísticas o argumentativas. También puede delimitarse la problemática a ser tratada aquí indagando si las condiciones que cumplimos cuando argumentamos, según el planteo de la pragmática trascendental del lenguaje, valen también fuera de la argumentación y si esta validez es también allí efectivamente categórica. Algunas objeciones, como se verá en el transcurso de este trabajo, sostienen que debería hablarse más bien de una validez hipotética, restringida a quienes efectivamente eligen involucrarse en intercambios discursivos. Una respuesta a este tipo de reparos deberá contemplar la posibilidad de una obligación de argumentar fuera del discurso y si existe algún tipo de coerción normativa en las acciones (prima facie) no lingüísticas.

II. LA DISCUSIÓN EN TORNO AL ALCANCE NORMATIVO DE LAS REGLAS DEL DISCURSO

Este problema tiene algunos antecedentes importantes. Si bien no ha sido tratado explícitamente como se lo hará aquí, ha sido abordado largamente por Apel en una discusión que mantuvo con Karl-Heinz Ilting ${ }^{5}$ sobre lo que se llamó

5 Véase K.-H. Ilting, «Der Geltungsgrund moralischer Normen», en W. Kuhlmann und D. 
la transferencia de la obligatoriedad o la continuidad de la obligatoriedad de las normas, fundamentadas pragmático-trascendentalmente, hacia el ámbito de las acciones en el mundo de la vida. El problema tal como se lo presentó en esa discusión giraba en torno a la pregunta de si las reglas que reconocemos necesariamente como participantes en una argumentación son igualmente obligatorias cuando abandonamos ese rol de argumentantes y adoptamos otros roles en el mundo de la vida, roles que no implican prima facie a la argumentación en ningún sentido.

Los planteos de Apel han mantenido, como se dijo, la pretensión de una continuidad entre la normatividad de las reglas del discurso y las acciones del mundo de la vida y, por lo tanto, la validez categórica de estas reglas. También quienes han seguido casi al pie de la letra los planteos de la pragmática trascendental y la ética del discurso han dado por sentado una continuidad no problemática entre la normatividad que las reglas del discurso establecen y las acciones de los hombres. ${ }^{6}$ Como se dijo, es esta una continuidad que debe darse por sentado si quiere hablarse de algo más que de una ética para el discurso simplemente y no una ética universal para todos los hombres, tal como, por ejemplo, está planteada en la ética kantiana y cualquiera de las propuestas de fundamentación ética que se precien de tales.

Sin embargo, han existido una serie de autores que han puesto explícitamente en duda esta continuidad. No sólo los planteos como los del mencionado Ilting, sino también ciertos reparos que ha sugerido Jürgen Habermas ${ }^{7}$ rechazan la continuidad mencionada. La particularidad que presenta la figura de Habermas en este punto es digna de mención, pues ha sido Habermas quien, junto con Apel, ha dado lugar al desarrollo de la ética del discurso. De todas formas, si bien las críticas que Habermas presenta niegan la continuidad que debe existir necesariamente entre los presupuestos del discurso y las acciones, él no rechaza la idea de que debe existir alguna forma de continuidad. Habermas sigue siendo, más allá de todos los cambios que ha ido experimentando

Böhler, Kommunikation und Reflexion. Zur Diskussion der Transzendentalpragmatik Antworten auf Karl-Otto Apel. Frankfurt am Main: Suhrkamp, 1982 y K.-O. Apel, «Faktische Anerkennung oder einsehbar notwendige Anerkennung? Beruht der Ansatz der transzendentalpragmatischen Diskursethik auf einem intellektualistischen Fehlschluß?», en Id. (Hg.), in Verbindung mit R. Pozzo, Zur Rekonstruktion der praktischen Philosophie. Gedenkschrift für Karl-Heinz Ilting. Stuttgart-Bad Cannstatt: Frommann-holzboog, 1990.

6 Véase W. Kuhlmann, Reflexive Letztbegrünndung, Untersuchungen zur Transzendentalpragmatik. Freiburg: Alber, 1985 y D. Böhler, Rekonstruktive Pragmatik. Von der Bewußtseinsphilosophie zur Kommunikationsreflexion: Neubegründung der praktischen Wissenschaften und Philosophie. Frankfurt am Main: Suhrkamp, 1985.

7 Cf. J. Habermas, Moralbewusstein und kommunikatives Handeln. Frankfurt am Main: Suhrkamp, 1983, pp. 95-96. 
su pensamiento, de la idea de que algunas de las coerciones normativas que se presentan como presupuestos en la argumentación deben ser llevadas a las acciones no argumentativas de los hombres. Más bien lo que parecería afirmarse en su obra es que dicha continuidad debe ser establecida con medios especiales y no desde los presupuestos de la argumentación misma.

Otros autores cercanos a la constelación habermasiana han puesto en cuestión de una manera más radical la idea de llevar las exigencias de la argumentación a las acciones no lingüísticas, al punto de rechazar la noción misma de una ética del discurso. ${ }^{8}$ De todas maneras, más allá de las diferencias que puedan existir entre estas objeciones contra la idea básica de Apel, ellas presentan algunas coincidencias. Tal vez la más importante sea la idea de que no se puede fundamentar de manera última una teoría ética entendida ésta como una reconstrucción de los presupuestos pragmáticos del discurso argumentativo con claros contenidos ético-normativos. A esta idea, Habermas la ha complementado con la sugerencia de que no sólo no es posible una fundamentación última de principios ético normativos, sino que tampoco es necesaria tal fundamentación. La causa de esta irrelevancia es que, como dice el propio Habermas, una fundamentación última no puede «quebrar la resistencia del escéptico consecuente contra toda forma de moral raciona $\rangle^{9}$ como la que la ética del discurso representa. Es decir, para Habermas no es necesaria una fundamentación última de la ética, pues ésta no puede hacer que el escéptico que no argumenta adopte la argumentación como forma de resolver la legitimidad de las normas. Tengamos o no una ética sólidamente fundamentada, no podremos lograr que aquellos que se niegan a comprometerse con la argumentación como salida éticamente legítima adopten esta forma de solucionar los conflictos. Y como la razón práctica tiene como objetivo primordial, desde la perspectiva habermasiana, no sólo señalar qué principios o normas son legítimas o que procedimientos podemos considerar para legitimarlas, sino también lograr que todas las acciones de los hombres se sometan efectivamente a sus directivas, toda fundamentación es inútil. El problema ético debe resolverse con la ayuda de otros ámbitos de la razón práctica tales como la política y el derecho parece pensar Habermas, ${ }^{10}$ y no sólo con la fundamentación de un procedimiento de legitimación de normas, en este caso con la reconstrucción de un conjunto de presupuestos de la argumentación.

8 Cf. A. Wellmer, Ethik und Dialog. Elemente des moralischen Urteil bei Kant und in der Diskursethik. Frankfurt am Main: Suhrkamp, 1986.

9 Cf. J. Habermas, Op. cit., p. 95.

10 Véase especialmente J. Habermas, Faktizität und Geltung. Beiträge zur Diskurstheorie des Rechts und des demokratischen Rechsstaats. Frankfurt am Main: Suhrkamp, 1992, cap. III y IV. 
La figura del «escéptico no argumentante», tal como la presenta Habermas, representa un problema central a la cuestión tratada aquí, es decir, la transferencia de la normatividad de las reglas del discurso a los problemas del mundo de la vida. Podríamos decir que el escéptico que no argumenta quiebra dicha transferencia, relativiza la validez de las obligaciones que las reglas del discurso poseen y, por lo tanto, minimiza la relevancia general de una ética del discurso. Podríamos decir que el escéptico no adopta el rol de argumentante y, por lo tanto, las coerciones normativas que la pragmática trascendental muestra como inevitables dentro del discurso no lo afectan, pues él no adopta ese rol.

Existe una diferencia entre las formas clásicas de escepticismo que dentro de las discusiones tradicionales se habían contemplado y esta nueva forma de escéptico que presenta Habermas. En muchas de las discusiones que se llevan adelante dentro del marco de la pragmática trascendental, aparecen diferentes formas de escepticismo, todas dirigidas contra ámbitos específicos de la pragmática. Por mencionar un caso cercano, Habermas representa una forma de escepticismo centrado en la posibilidad de reconstruir de manera acabada y última un conjunto de presupuestos de la argumentación tal como piensa Apel. Esta posibilidad está en el centro de las discusiones en torno a una pragmática universal versus una pragmática trascendental del lenguaje. ${ }^{11}$

Pero estas formas de escepticismo a las que nos referimos tienen todas en común el hecho de que ellas están vehiculizadas argumentativamente. De un modo obvio, las críticas que estas variantes del escepticismo presentan no pueden estar sino articuladas discursivamente y por ello representan una gran ventaja para las estrategias argumentativas de la pragmática trascendental. En la medida en que se articulan lingüisticamente, las objeciones de estos escépticos no representan un problema para la pragmática trascendental del lenguaje. A estas críticas puede mostrárseles, mediante una reflexión estricta sobre aquello que ellas mismas hacen con el acto de discutir y elevar objeciones, que en la dimensión pragmática de la enunciación de sus juicios necesariamente han reconocido como válido aquello que discuten y ponen en entredicho en la dimensión proposicional de sus afirmaciones. De esta manera, queda en evidencia la inconsistencia pragmática en la que incurren y la consecuente invalidez de sus objeciones. La indicación de la inconsistencia pragmática es una de las principales estrategias argumentativas de la pragmática trascendental contra todos sus oponentes filosóficos. ${ }^{12}$

11 Véase J. Habermas, «Was heißt Universalpragmatik?», en K.-O. Apel (Hrsg.), Sprachpragmatik und Philosophie. Frankfurt am Main: Suhrkamp, 1976, pp. 174-272. Para una discusión entre ambos tipo de pragmática véase también K.-O. Apel, Auseinandersetzungen in Erprobung des transzendentalpragmatischen Ansatzes, pp. 649-838.

$12 C f$. M. Kettner, "Ansatz zu einer Taxonomie performativer Selbstwidersprüche», en A. Dorschel et al., Transzendentalpragmatik. Ein Symposion für Karl-Otto Apel. Frankfurt 
Sin embargo, esta nueva forma de escéptico que pone en escena Habermas definitivamente no argumenta. Por ello, mostrarle a esta forma de escepticismo, como en ocasiones hace Apel, ${ }^{13}$ que existen en toda argumentación presupuestos irrebasables que es necesario reconocer y que representan en sí mismos reglas prácticas para el comportamiento, resulta insuficiente para contrarrestar aquello que esta forma de escepticismo representa. Es insuficiente desde el mismo momento en que esa estrategia apeliana descansa fundamentalmente en el hecho de que su oponente debe presentarse a sí mismo argumentando. Pero en este caso, la figura que Habermas presenta no argumenta. De allí la fuerza que parece presentar esta figura. Para asegurar la continuidad de la normatividad entre las reglas del discurso y las acciones del mundo de la vida es insuficiente la estrategia apeliana de recurrir a aquello que el escéptico reconoce ya con su argumentación. La insuficiencia de dicha estrategia radica en que aquí no existe a primera vista argumentación alguna.

Objeciones de este tipo contra la ética del discurso sostienen en el fondo que el juego de lenguaje de la argumentación es un juego de lenguaje como cualquier otro y que un actor puede optar qué tipo de juego de lenguaje quiere jugar. Si juega el juego de la argumentación, debe acatar como obligatorias las normas que hemos reconstruido de manera pragmático trascendental, y que se encuentran necesariamente reconocidas por todo aquel que argumenta. Pero, según estas objeciones, quien no opta por este tipo de juego de lenguaje, no se ve obligado a adoptar las reglas que lo rigen necesariamente.

Este tipo de críticas representan, como se dijo, un problema esencial para la transferencia de la normatividad de las reglas del discurso y con ello para la totalidad de una ética del discurso fundamentada pragmático-trascendentalmente. Lo que estos reparos procuran hacer es transformar la validez categórica de las reglas de la argumentación en una validez de tipo hipotética: la validez de las reglas de la argumentación dependería de la voluntad de argumentar o de introducirse en el discurso. Si un agente decide voluntariamente introducirse en una argumentación y responder a las exigencias de los presupuestos del discurso esas reglas son válidas para él. Pero, según estas críticas, su validez se suspendería cuando permanece por fuera de la argumentación y no tiene intenciones de ingresar en ella.

Así se podría decir que cuando argumentamos debemos reconocer como necesarios determinados presupuestos que no podemos poner en discusión.

am Main: Suhrkamp, 1993, pp. 187-211. Para una discusión de la inconsistencia pragmática o autocontradicción performativa puede verse también M. Jay, «The Debate over Performative Contradiction: Habermas vs. the Post-structuralist.», en A. Honneth et. al. (Hrsg.), Zwischenbetrachtungen. Im Prozess der Aufklärung. Frankfurt am Main: Suhrkamp, 1989.

13 Cf. K.-O. Apel, Transformation der Philosophie, II, pp. 410 y ss. 
En el ámbito de la argumentación esos presupuestos gozan de una validez absoluta, categórica. Cualquier intento de ponerlos en cuestión conduciría irremediablemente a cometer una inconsistencia pragmática y anularía el sentido de lo que argumentamos. Sin embargo, debemos reconocer sin demasiado esfuerzo que no siempre se argumenta. Los verdaderos intercambios argumentativos parecen ser pequeñas «islas» en nuestra vida cotidiana. ${ }^{14}$ Este último tipo de situaciones servirían para sostener la idea de que la validez incondicional de los presupuestos de la argumentación, que se presenta como tal cuando verdaderamente intercambiamos argumentos, se suspende cuando realizamos otro tipo de actividades que no sean lingüísticas. Es decir, la validez de dichos presupuestos sería en verdad condicional. Está atada al hecho de que efectivamente nos introduzcamos en discusiones en donde se efectúan críticas y se respaldan posiciones con razones de peso (o no). La validez de los presupuestos del discurso dependería de la decisión que nosotros tomemos de entrar en discursos, de argumentar o no argumentar.

Resumiendo, podemos decir que el conjunto de las objeciones examinadas ponen en entredicho la relevancia de la totalidad del proyecto práctico de la

14 Es conveniente dejar en claro aquí lo que se entiende por «argumentación» y «discurso» en los planteos pragmáticos de Apel y Habermas, pues es la caracterización que se adoptará a lo largo de todo este trabajo. Cuando Habermas y Apel hablan de «argumentación» no se refieren a cualquier forma de manifestación lingüística o intercambio dialógico sino a aquella en donde dos o más interlocutores elevan pretensiones de validez e intercambian argumentos y razones defendiendo las pretensiones por ellos elevadas, buscando la solución a un conflicto o la verdad de un problema. Cito las palabras de Habermas: «Llamo argumentación al tipo de habla en que los participantes tematizan las pretensiones de validez que se han vuelto dudosas y tratan de desempeñarlas o de recusarlas por medio de argumentos. Una argumentación contiene razones que están conectadas de forma sistemática con la pretensión de validez de la manifestación o emisión problematizadas»., Theorie des kommunikativen Handelns. Bd. I, Frankfurt am Main: Suhrkamp, 1981, p. 38. Las cursivas son de Habermas. Por otra parte, el «discurso» representa una forma de argumentación en la cual los interlocutores dan por cumplidas las condiciones de una situación ideal de habla, libre de cualquier tipo de coacción externa o interna. Es decir, en el discurso los participantes presuponen las condiciones de una total simetría entre ellos. En palabras de Habermas: «Sólo en los discursos teóricos, prácticos y explicativos tienen que partir los participantes en la argumentación del presupuesto (a menudo contrafáctico) de que se cumplen con suficiente aproximación las condiciones de una situación ideal de habla. Sólo hablaré, pues, de 'discursos' cuando el sentido mismo de la pretensión de validez que se ha tornado problemática fuerce conceptualmente a los participantes a suponer que en principio podría alcanzarse un acuerdo racionalmente motivado, significando aquí 'en principio' la siguiente reserva idealizadora: con tal que la argumentación fuera suficientemente abierta y durara el tiempo suficiente». Theorie des kommunikativen Handelns, Bd. I., ed. cit., p. 71. También se ha hablado en este mismo sentido de «discurso argumentativo». Véase al respecto D. Böhler [junto con H. Gronke], «Diskurs», en Historisches Wörterbuch der Rethorik, hg. von G. Ueding, mitbegrundet von W. Jens. Redaktion: G. Kalivoda, F.-H. Robling, H. Meyer., Bd. 2. Tübingen: Max Niemeyer Verlag, 1994, p. 812. 
pragmática trascendental. Este proyecto, denominado ética del discurso, pretende reconstruir un conjunto de coerciones normativas a partir del discurso y pensarlas como obligatorias para las acciones del mundo de la vida. Por ello, la refutación de estas objeciones no implica sólo fundamentar la idea central a la ética del discurso (en su versión apeliana) de que existe una continuidad en la normatividad entre las reglas de la argumentación y las acciones del mundo de la vida. Ello significa además establecer que estas reglas poseen una validez categórica - tal como, por ejemplo, el imperativo kantiano- y no una validez hipotética para aquellos que se muestran dispuestos a aceptar las coerciones del discurso. La ética del discurso pretende validez universal e incondicional y no una validez acotada para aquellos que aceptan sus presupuestos. Ello quiere decir que las coerciones que se reconstruyen como presuposiciones irrebasables no valen sólo para los que argumentan, sino para todas las acciones en general.

\section{Karl-Otto Apel y El Ámbito de VAlidez de LAS REgLAS DEL DISCURSO}

La respuesta de Apel a este problema pone en juego una parte fundamental del nuevo planteo desarrollado por la pragmática trascendental del lenguaje, es decir, lo que él denomina una «crítica trascendental del sentido». Sin embargo, a mi entender, Apel la aplica de una manera insuficiente, desaprovechando parte del potencial de aquello que ha descubierto. En última instancia, Apel no desarrolló en toda su extensión las implicancias pragmático-trascendentales de aquellos argumentos que él mismo esgrime contra un escéptico «no argumentante» y que parece poner en entredicho la totalidad del desarrollo práctico de la pragmática trascendental del lenguaje. Sobre este punto, Apel se concentró en desarrollar exclusivamente una pragmática trascendental del lenguaje más que ampliar dicho programa de investigación también a las acciones no lingüísticas de los hombres, como, por ejemplo, abrir una ventana o salir a correr por el parque. En este sentido, puede afirmarse que existe aquí un campo muy fecundo de ideas que han sido exploradas, ${ }^{15}$ pero que es necesario poner en relación sistemática con el problema aquí abordado y desarrollar en su totalidad.

Volviendo sobre la solución que Apel presenta al problema del escepticismo no argumentativo, Apel menciona que objeciones como las que Habermas ha formulado no pueden ser planteadas en un paradigma filosófico que ha

$15 C f$. D. Böhler, Op. cit; A. Øfsti, «Ist diskursive Vernunft nur eine Sonderpraxis? Betrachtungen zum 'Verbindlichkeitstransfer' von transzendental-reflexiv (letz-) begründeten Normen», en K.-O. Apel und M. Kettner (Hrgs.), Zur Anwendung der Diskursethik in Politik, Recht und Wissenschaft. Frankfurt am Main: Suhrkamp, 1992 e Id., «Das Sprachspiel-Idiom und die Einheit der Vernunft. Bemerkungen zu Apels Wittgensteinkritik», en A. Dorschel, Traszendentalpragmatik. Frankfurt am Main: Suhrkamp, 1993. Véase también A. Damiani, Handlungswissen. Eine transzendentale Erkundung nach der sprachpragmatischen Wende. Freiburg / München: Karl Alber, 2009, especialmente pp 82 -91.

Contrastes vol. XIX-N² (2014) 
experimentado un giro pragmático-lingüístico. Una objeción como la que realiza Ilting o Habermas, y otra también hecha por Popper, ${ }^{16}$ sólo pueden ser efectuadas por alguien que piensa todavía dentro de los parámetros del paradigma del solipsismo de la conciencia, propio de la Modernidad o que no ha adoptado completamente el nuevo paradigma del lenguaje. De aquí que se vea como necesario, frente a las críticas hechas por estos autores, volver sobre el trasfondo pragmático trascendental sobre el cual Apel proyecta el alcance normativo de las reglas de la argumentación. Y en verdad, no sólo sobre el trasfondo pragmático trascendental tal como está presentado en Apel, es decir como una reconstrucción de los presupuestos de la argumentación con sentido, sino ya sobre una ampliación de esta estrategia conceptual aplicada ahora, no a la argumentación con sentido, sino directamente a las acciones con sentido (o intencionales podríamos también decir).

Desde el punto de vista del paradigma filosófico del solipsismo de la conciencia, en el marco del cual, según Apel, los autores mencionados realizan sus objeciones, se podría concebir un individuo que lleva a cabo siempre sus acciones sin recurrir nunca al discurso o alguna otra forma de lenguaje. Ello no quiere decir naturalmente que no se pueda pensar en alguien que actúa simplemente sin entablar alguna forma explícita de argumentación o discurso. Sostener esto sería claramente un sinsentido y cualquier persona con sus facultades plenas podría señalarlo y tendría con ello razón. En todo momento vemos personas que realizan acciones sin recurrir explicitamente a alguna forma de lenguaje.

En las discusiones que Apel entabló con Ilting, Habermas o Popper ha señalado más bien que las críticas y las posiciones de estos autores parten de los supuestos fundamentales del solipsismo metodológico no porque planteen que es posible concebir un sujeto que a primera vista no discute o argumenta. Los reparos apelianos a los autores señalados van dirigidos a la idea que ellos en el fondo parecen avalar, es decir, la idea de que es posible pensar o decidir alguna acción sin presuponer el discurso y las reglas que lo sostienen y constituyen. La objeción de Apel procura señalar que si bien es posible concebir una persona que actúa sin recurrir explicitamente a alguna forma de lenguaje, no es posible pensar desde un paradigma pragmático lingüístico en un sujeto que piensa o decide alguna acción sin presuponer una forma de discurso. Teniendo en cuenta esta crítica de Apel, se puede ver cómo estos autores parecerían estar todavía encuadrados en un paradigma filosófico que no ha asumido aun las implicancias teóricas del giro pragmático-hermenéutico-lingüístico que Apel procura continuar. Parece ser común a ellos el hecho de concebir un pensa-

$16 C f$. K. Popper, Die offene Gesellschaft und ihre Feinde, Bd. II. München: Francke Verlag, 1980, pp. 432-433. 
miento sin lenguaje, una conciencia que opera todavía con pensamientos que «después» se articulan en conceptos lingüísticos, una razón no estructurada esencialmente como lenguaje. La constitución del sentido (de las acciones o del lenguaje) parecería ser todavía para ellos la facultad de una conciencia solitaria pre- o a-lingüística.

Contra las posiciones de los autores antes mencionados Apel moviliza una parte esencial del proyecto de la pragmática trascendental del lenguaje, es decir, una crítica trascendental del sentido o una crítica reflexivo dialógica del sentido. ${ }^{17}$ Brevemente, según ella no es posible pensar ni actuar, y por lo tanto tampoco atribuir un sentido a los sucesos del mundo y a nuestras acciones, sin presuponer necesariamente nuestra participación en una comunidad de lenguaje. Incluso nuestra identificación como personas depende fundamentalmente de ello. ${ }^{18}$

Sin embargo, la crítica trascendental del sentido tal como Apel la presenta en sus primeros escritos no es aplicada en toda su extensión o desarrollada con la suficiente sistematicidad como para extenderla a aquello que queda al descubierto con el problema del escéptico que no argumenta. Falta en Apel, y esto es decisivo, un examen sistemático de las acciones prima facie no lingüísticas bajo las premisas de una crítica trascendental del sentido. Apel menciona que toda acción y decisión, aun las hechas en la más absoluta soledad de la conciencia, presuponen ya la presencia de una comunidad de lenguaje. Sin embargo allí terminan sus indicaciones. No es posible encontrar en Apel un desarrollo más acabado de cómo se concibe una acción prima facie no lingüística bajo la óptica de una pragmática trascendental. La labor reconstructiva que Apel realiza en el discurso extrayendo de éste un conjunto de presupuestos irrebasables no está extendida a las acciones no lingüísticas. Apel llega a las puertas de esta empresa, pero no se introduce en su desarrollo. Desde esta perspectiva

$17 C f$. D. Böhler, «Dialogreflexive Sinnkritik als Kernstück der Transzendentalpragmatik. Karl Otto Apels Athene im Rücken», en D. Böhler, M. Kettner, G. Skirbekk (Hrsg.): Reflexion und Verantwortung. Auseinandersetzungen mit Karl-Otto Apel. Frankfurt am Main: Suhrkamp, 2003, p. 16. Véase también D. Böhler, «Wohin führt die pragmatische Wende. Norwegische Diskussionsbeiträge in transzendentalpragmatischer Sicht», en Id., T. Nordenstam und G. Skirbekk (Hrsg.), Die pragmatische Wende. Sprachspielpragmatik oder Transzendentalpragmatik? Frankfurt am Main: Suhrkamp, 1986, p. 267 y K.-O. Apel, «Lässt ethische Vernunft von strategischer Zweckrationalität unterscheiden? Zum Problem der ratioanlität sociales Kommunikation und Interaktion», en Archivio di Filosofia, Anno LI 1983, N. 1-3, p. 420. Existe traducción castellana: K.-O. Apel, «¿Es posible distinguir la razón ética de la racionalidad estratégico-teleológica? Acerca del problema de la racionalidad de la comunicación e interacción sociales», en Id., Estudios Éticos. Barcelona: Alfa, 1986.

18 Cf. K.-O. Apel, Transformation der Philosophie, I, pp. 60-61. 
podemos decir que hay en el pensamiento de Apel in nuce no sólo una teoría pragmático-trascendental de la acción, sino incluso toda una ontología social.

Esta situación puede apreciarse con entera claridad en el tratamiento del supuesto carácter hipotético de las reglas de la argumentación mencionado anteriormente. En vez de abordar esta situación directamente desde la perspectiva más amplia de una crítica trascendental del sentido, Apel parece en ocasiones hacerlo simplemente desde los presupuestos de la argumentación explícita, es decir, desde un punto de vista más estrecho. ${ }^{19}$ Apel, en el marco de la discusión con Popper, responde de la siguiente manera al problema de la voluntad de argumentar y la validez de las reglas del discurso: «La voluntad racional puede y tiene que presuponerse en cada discusión filosófica sobre fundamentos pues, en caso contrario, la discusión misma carece de sentido».

Más adelante continúa Apel:

Con respecto a la argumentación, en tanto que filósofos, no podemos renunciar a nuestra voluntad de argumentar. Por ello la voluntad de argumentar no está empíricamente condicionada, sino que es condición trascendental de posibilidad de toda discusión sobre condiciones empíricas aceptadas hipotéticamente. ${ }^{20}$

Sin duda, lo que Apel menciona en estos fragmentos no puede ser discutido sin negar lo que establece la pragmática trascendental del lenguaje en torno al saber performativo que acompaña a los actos de habla y al conjunto de presupuestos que forman parte de manera constitutiva de la argumentación con sentido. Pero Apel continúa aquí refiriéndose de alguna manera a un sujeto que argumenta, de una manera escéptica, pero que argumenta al fin. Por lo tanto, puede mostrársele a este individuo que comete, en efecto, una autocontradicción performativa en tanto niega explícitamente aquello que debe presuponer para que su negación tenga sentido.

De esta manera, el problema de la continuidad en la normatividad de las reglas del discurso es percibido por Apel primero como un problema práctico o de aplicación, sin darse cuenta de las presuposiciones problemáticas que subyacen en el hecho de abordarlo de esa manera. Por ejemplo, pensar que un sujeto puede identificarse a sí mismo, pensar o actuar con sentido sin presuponer una comunidad de lenguaje, tal como lo establece la crítica trascendental del sentido antes mencionada. Pero luego, Apel se da cuenta de estas presuposiciones problemáticas y aborda entonces el problema efectivamente desde esa perspectiva. Así entonces dice:

19 Cf. K.-O. Apel, Transformation der Philosophie, II, p. 415.

20 K.-O. Apel, Transformation der Philosophie, II, p. 415. Las cursivas son de Apel. 
Me parece que esto es lo que Popper presupone en su argumentación, manifestando con ello de forma muy interesante, a mi juicio, que parte del supuesto fundamental del «solipsismo metódico», como casi todos los clásicos de la filosofía desde Descartes (¿o desde Agustín?). Es decir, parte de la idea de que podemos pensar y decidir con sentido antes de haber reconocido, al menos implícitamente, las reglas de la argumentación como reglas de una comunidad crítica de comunicación; o bien -lo que conduce a la misma situación- que podemos filosofar sobre la comunicación crítica desde un punto exterior a ella. ${ }^{21}$

La última parte del pasaje (aquella que dice «podemos filosofar sobre la comunicación crítica desde un punto exterior a ella») parece sugerir que Apel piensa aquí todavía en una persona que argumenta. Sin embargo, la primera parte de ese fragmento (aquella que dice «podemos pensar y decidir con sentido antes de haber reconocido, al menos implícitamente, las reglas de la argumentación como reglas de una comunidad crítica de comunicación») no deja dudas de que Apel se refiere también al escéptico que incumbe a esta discusión, es decir, al que actúa y no al que discute. Pero lo interesante es que aquello que queda al descubierto aquí y que forma parte esencial del proyecto de una pragmática trascendental del lenguaje, es decir, una crítica trascendental del sentido o una crítica reflexivo dialógica del sentido, como la llama Böhler, ${ }^{22}$ no es aplicado en toda su extensión o desarrollado con la suficiente sistematicidad como para refutar al escéptico no argumentante.

La posición tomada al respecto en este trabajo es que esta manera propiamente apeliana de tratar esta problemática resulta completamente insuficiente para refutar al escéptico habermasiano no argumentante. En última instancia resulta también insuficiente para asegurar la validez categórica de las reglas del discurso. En este sentido, la postura defendida aquí es que el problema presentado por esta clase de escepticismo y las objeciones con respecto a la validez hipotética de las reglas sólo puede ser resuelto de una manera acabada desde la perspectiva más amplia de una crítica trascendental del sentido de las acciones en general y desarrollar en toda su extensión qué implica concebir a partir de un punto de vista pragmático trascendental las acciones humanas como tales.

La estrategia apeliana de recurrir a aquello que siempre hemos de reconocer necesariamente cada vez que argumentamos para que nuestro discurso tenga sentido puede ser provechosa - ello ha sido puesto en juego y acreditado

21 K.-O. Apel, Transformation der Philosophie, II, p. 414. Las cursivas son de Apel.

$22 C f$. D. Böhler, «Dialogreflexive Sinnkritik als Kernstück der Transzendentalpragmatik. Karl Otto Apels Athene im Rücken», en D. Böhler, M. Kettner, G. Skirbekk (Hrsg.): Reflexion und Verantwortung. Auseinandersetzungen mit Karl-Otto Apel. Frankfurt am Main: Suhrkamp, 2003, p. 16. 
en las controversias con todos los filósofos contemporáneos que han discutido la posibilidad de una fundamentación última a nivel argumentativo- mientras las objeciones que se pongan en juego refieran precisamente a un plano explicitamente argumentativo. Pero por las objeciones que representa el escéptico que no argumenta en el caso de Habermas parece más que claro que no puede sino hacérseles frente con una ampliación del espectro de la pragmática trascendental, referido, no ya al plano de la argumentación explícita, sino al plano de las acciones humanas en general. Esto puede hacerse, como ya se dijo, desde una crítica trascendental o reflexivo-dialógica del sentido de estas acciones.

\section{HACIA UNA RECONSTRUCCIÓN PRAGMÁTICO-TRASCENDENTAL}

\section{DE LAS ACCIONES NO LINGÜÍSTICAS}

La estrategia para contrarrestar al escepticismo «no argumentante» y poder pensar en una continuidad en la normatividad asegurando la validez categórica de las reglas de la argumentación debe ser, como se ha dicho, diferente a la presentada en ocasiones por Apel. Solo cambiando el procedimiento apeliano se podrá dar una base sólida a todo el proyecto práctico de la pragmática trascendental del lenguaje. Si el escéptico argumenta, se recurre a aquello que presupone necesariamente para que su propia argumentación tenga sentido. Si no argumenta, pero realiza alguna forma de acción, allí es donde debe buscarse una solución a la problemática aquí presentada.

No obstante, a pesar de ser diferente, el plan que se pone en juego en este trabajo no difiere en sus rasgos esenciales de aquello que se presenta como distintivo de la pragmática trascendental del lenguaje. Si bien no se buscará ya la solución al problema planteado por el escepticismo no argumentante en los presupuestos de la argumentación explícita se los buscará de todas formas en los presupuestos de un tipo de acción, sólo que no es, en una primera instancia, la acción propiamente lingüística. De esta manera, las principales estrategias metodológico-argumentativas de este estudio se mantienen como una reconstrucción de las condiciones de posibilidad, es decir, de los presupuestos necesarios e irrebasables de una práctica, sólo que en este caso no es prima facie la de la argumentación.

Desde este punto de vista, la estrategia correcta está in nuce en la obra del propio Apel. De hecho él mismo, como se dijo, la pone en juego frente a la figura de este escéptico que no argumenta tal como aparece en Habermas y en las discusiones con el racionalismo crítico de Popper y Albert. ${ }^{23}$ Sólo que Apel no ha continuado desarrollando esta estrategia en todo su alcance. Tampoco

23 Véase K.-O. Apel, Transformation der Philosophie, II, p. 411 y ss.; K. Popper, Die offene Gesellschaft und ihre Feinde, II Bde. München: Francke Verlag, 1980 y H. Albert, Traktat über kritische Vernunft. Tübingen: Mohr, 1968. 
es posible encontrar un desarrollo más amplio de esta idea en la mayoría de los autores que han continuado desarrollando los planteos de la pragmática trascendental, como por ejemplo Kuhlmann, Kettner, Burckhart, ${ }^{24}$ entre otros.

Una excepción en este punto lo constituye la obra de Dietrich Böhler. Böhler ha continuado explorando el programa de la pragmática trascendental en ese sentido abierto por Apel y así a hablado de una pragmática trascendental «en sentido amplio». ${ }^{25}$ Lo que con este nuevo concepto se quiere señalar es la posibilidad de llevar el carácter reconstructivo de la pragmática sobre los presupuestos necesarios e irrebasables, no sólo de la argumentación con sentido, sino sobre el trasfondo más amplio de las acciones humanas en general. Allí se encuentra a mi entender la solución definitiva al problema que representa el escéptico habermasiano que no argumenta.

En este sentido, sobre el trasfondo de una pragmática trascendental en sentido amplio, lo que puede observarse es que la transferencia de la normatividad de las reglas del discurso a las acciones de los hombres en el mundo de la vida puede establecerse reconstruyendo en estas últimas acciones los mismos presupuestos y las mismas coerciones normativas que se reconstruyen en el discurso explícitamente argumentativo. De esta forma es posible asegurar esa continuidad buscada por la ética del discurso y con ella finalmente la validez categórica de esas reglas.

Tomando esta perspectiva como punto de partida, puede probarse la idea de que el actor no argumentante, en tanto simplemente actúa, ya presupone también necesariamente una comunidad de comunicación y todos sus presupuestos trascendentales. En este sentido, podemos decir que en la acción no argumentativa se asumen los mismos presupuestos normativos que la acción lingüística con sentido. ${ }^{26}$ Así, por ejemplo, el actor con su acción también eleva pretensiones de validez, tal como las que Habermas ha reconstruido para las acciones lingüísticas. ${ }^{27}$

24 Véase W. Kuhlmann, op. cit.; K.-O. Apel, M. Kettner (Hrgs.), Zur Anwendung der Diskursethik in Politik, Recht und Wissenschaft. Frankfurt am Main: Suhrkamp, 1992 y H. Burckhart, Sprachreflexion und Transzendentalphilosophie. Würzburg: Königshausen \& Neumann, 1991.

$25 C f$. D. Böhler, Rekonstruktive Pragmatik, pp. 175-355.

26 En este sentido se dirigen las investigaciones de D. Böhler en Rekonstruktive Pragmatik y también posteriormente en la distinción entre los roles del «interlocutor discursivo» y el «actor en el mundo de la vida». Sobre este último punto véase D. Böhler, «Glaubwürdigkeit des Diskurspartners. Ein (wirtschaft -) ethischer Richtungsstoß der Berliner Diskurspragmatik und Diskursethik», en T. Bausch, D. Böhler, T. Rusche (Hg.), Wirtschaft und Ethik. Strategien contra Moral? Münster: Lit Verlag, 2004.

$27 C f$. J. Habermas, «Was heisst Universalpragmatik?», en Apel, K.-O., Sprachpragmatik und Philosophie. Frankfurt am Main: Suhrkamp, 1976, pp. 175 y ss. 
Puede presentarse aquí un ejemplo de una acción no lingüística para intentar reconstruir en ella algunas de pretensiones de validez mencionadas por Habermas (verdad, corrección normativa y sinceridad o veracidad ${ }^{28}$ ). Podría pensarse en una persona que se dispone a podar un árbol que se encuentra en el frente de su casa y dice internamente: «voy a podar el árbol de la vereda». Se debería en ese acto poder identificar las pretensiones de validez nombradas anteriormente. Pues bien, bajo ese punto de vista puede decirse que quien se propone podar un árbol que se encuentra en el frente de su casa eleva, primero, una pretensión de verdad. En efecto, con su acción de poda el individuo afirma, por ejemplo, que existe verdaderamente en el mundo un árbol al que podar, que él tiene una casa con un árbol en el frente o que posee los elementos necesarios para llevar a cabo su actividad.

Pero no sólo es posible reconstruir una pretensión de verdad en su acción sino también una pretensión de corrección normativa. Así, el sujeto que se propone podar su árbol presupone que su acción se adapta a los códigos municipales de poda o a los códigos de convivencia entre vecinos. Esa persona poda un árbol que le pertenece a él (no a su vecino), realiza dicha acción en el momento del año autorizado para ello y la efectúa pues puede hacerlo y no corresponde a la jurisdicción municipal hacer dicha tarea, por ejemplo. El sujeto realiza una acción que se adapta a la normativa en el marco de la cual es llevada a cabo.

Lo mismo puede decirse de la última pretensión mencionada, es decir, de la pretensión de sinceridad. Con su acción el sujeto afirma verdaderamente su intención de podar el árbol y no representa esa actividad una excusa para controlar las actividades de sus vecinos, no asistir al trabajo o escapar de alguna responsabilidad que tuviera en el marco de su familia. El sujeto pretende verdaderamente realizar esa acción y no otra cualquiera. Entonces, como puede verse a través del ejemplo, las pretensiones de validez no sólo es posible reconstruirlas en las acciones lingüísticas sino también en las acciones en principio no lingüisticas.

Pero entonces, finalmente, una vez que es posible reconstruir también en las acciones prima facie no lingüísticas de los hombres los mismos presupuestos normativos que en la argumentación explícita puede asegurarse de manera contundente la continuidad de estos presupuestos, tal como fue pensado originalmente por la pragmática trascendental del lenguaje, y de este modo afirmar de una manera consistente la validez categórica de las reglas del discurso.

28 Habermas se refiere también inicialmente a una cuarta pretensión de validez (la inteligibilidad), pero esta está referida explícita y exclusivamente al lenguaje. 


\section{Algunas COnClusiones}

Con la reconstrucción entonces de las coerciones antes presentadas se alcanzan los objetivos iniciales y primordiales planteados por este trabajo, pues se logra rastrear las mismas coerciones que existen en el discurso en la praxis no argumentativa. De esta manera se consigue probar la continuidad en la normatividad de las reglas del discurso en las acciones del mundo de la vida y se asegura también la validez categórica de los presupuestos de la argumentación, pues ellos no son sólo válidos para quien opta voluntariamente por el discurso explícito, sino para quien simplemente realiza cualquier tipo de acción con sentido.

A esta conclusión puede agregarse lo siguiente. Desde un punto de vista pragmático trascendental en sentido estricto quien negaba o discutía los presupuestos de la argumentación y, por lo tanto, anulaba el sentido de aquello que pretendía en el discurso, cometía, como se dijo, una inconsistencia pragmática. Ahora, quien rehúye el discurso necesario para resolver mediante razones las pretensiones que eleva implícitamente con su acción inicia un proceso patológico en el cual se niega los medios necesarios para identificar su acción como de un tipo específico y también para reconocerse a sí mismo como un actor, y ello significa nada menos que excluirse a sí mismo de la comunidad de los seres racionales, entendida ésta como la comunidad de aquellos seres que pueden dar razones y argumentos que justifican su accionar.

Esto último significa también que el juego del lenguaje de la argumentación no es un juego del lenguaje como cualquier otro que podamos optar por jugar o no. ${ }^{29}$ El juego de la argumentación es un juego en el cual nos encontramos inmersos en tanto simplemente actuamos y atribuimos un sentido a nuestras acciones, es decir, en última instancia, en tanto nos comportamos como seres racionales. ${ }^{30}$ Bajo este punto de vista, el juego trascendental del lenguaje funcionaría así como la posibilidad del individuo solitario de asegurarse de su existencia ${ }^{31} \mathrm{y}$ de autoidentificarse como un ser que realiza acciones con sentido. ${ }^{32}$ Así, mientras quienes impugnan la validez de las reglas dentro del discurso cometen una autocontradicción performativa, sustraerse a las obligaciones que impone el actuar con sentido sólo puede hacerse a costa de excluirse

29 Cf. K.-O. Apel, «Faktische Anerkennung oder einsehbar notwendige Anerkennung? Beruht der Ansatz der transzendentalpragmatischen Diskursethik auf einem intellektualistischen Fehlschluß?», p. 110.

30 Cf. Ibid., p. 80.

31 Cf. Id., Auseinandersetzungen in Erprobung des transzendentalpragmatischen Ansatzes, p. 74.

32 Cf. Ibid., p. 76. 
de la comunidad de los seres racionales capaces de participar en el proceso de resolución discursiva de las pretensiones de validez implícitas en sus actos.

De esta manera, finalmente, puede encontrarse una solución al problema central planteado en este estudio de la transferencia de la normatividad de las reglas del discurso y el presunto carácter hipotético de su validez. Pero con dicha solución, no sólo se da una respuesta a las importantes objeciones que se han hecho desde los planteos de Ilting o Habermas, sino que se amplía la perspectiva con respecto a los límites del proyecto pragmático trascendental y se asienta sobre bases sólidas el correlato práctico de éste.

Leando Paolicchi es Doctor en Filosofía (UNLA). Se desempeña como docente dentro de la Facultad de Humanidades así como también en la Facultad de Ciencias Económicas y Sociales de la Universidad Nacional de Mar del Plata (Argentina).

Lineas de investigación

Pragmática, filosofía política y filosofía contemporánea, especialmente referidas a la Escuela de Frankfurt.

Publicaciones recientes

«Discurso y Facticidad. Moral, Derecho y Política en la obra de Jürgen Habermas y KarlOtto Apel» y «Praxis, sentido y normatividad. Hacia una reconstrucción pragmática de las acciones humanas».

Dirección electrónica: leandropaolicchi@yahoo.com 
